\title{
The pREset Stent Retriever for Endovascular Treatment of Stroke Caused by MCA Occlusion: Safety and Clinical Outcome
}

\author{
B. J. Schwaiger $\cdot$ F. Kober $\cdot$ A. S. Gersing $\cdot$ \\ J. F. Kleine $\cdot$ S. Wunderlich $\cdot$ C. Zimmer $\cdot$ H. Poppert $\cdot$ \\ S. Prothmann
}

Received: 30 April 2014 / Accepted: 29 July 2014 / Published online: 12 August 2014

(C) Springer-Verlag Berlin Heidelberg 2014

\begin{abstract}
Purpose The purpose of this study was to analyze the safety and efficacy of the pREset device, a stent retriever system, for endovascular mechanical thrombectomy (MT) in acute ischemic stroke (AIS) after middle cerebral artery (MCA) occlusion.

Methods Retrospectively, 48 consecutive patients (mean age \pm standard deviation, $71.0 \pm 11.9$ years; 24 women) treated for acute MCA occlusion using pREset solely or in combination with other MT devices were identified. Recanalization success was evaluated using the modified thrombolysis in cerebral infarction score (TICI), and complications were detected by 24 -h follow-up computed tomography or magnetic resonance imaging. MCA anatomy was assessed in angiograms. Clinical outcome was evaluated with National Institutes of Health Stroke Scale (NIHSS) score at admission and discharge, and modified Rankin scale (mRS) score at discharge and follow-up.

Results Successful recanalization (TICI 2b/3) was achieved in 39 patients $(81.3 \%)$. Rate of procedure-related complications was $8.3 \%$. In four patients, a subarachnoid hemorrhage occurred $(8.3 \%)$, and parenchymal hematoma was

B. J. Schwaiger, MD $(\bowtie) \cdot$ F. Kober $\cdot$ A. S. Gersing, MD ·

J. F. Kleine, MD · C. Zimmer, MD · S. Prothmann, MD

Abteilung für Neuroradiologie, Klinikum rechts der Isar der

Technischen Universität München,

Ismaninger Str. 22,

81675 Munich, Germany

e-mail: benedikt.schwaiger@tum.de

S. Wunderlich, MD $\cdot$ H. Poppert, MD

Neurologische Klinik und Poliklinik, Klinikum rechts der Isar der

Technischen Universität München,

Ismaninger Str. 22,

81675 Munich, Germany
\end{abstract}

detected in four patients $(8.3 \%)$. None of those events was associated with clinical deterioration. MCA curvature significantly influenced recanalization success $(P<0.005)$.

Successful recanalization correlated significantly with lower NIHSS scores and favorable clinical outcome (mRS score $0-2)$ at discharge $(P<0.05)$. Mortality within 90 days was significantly lower in patients with TICI $2 \mathrm{~b} / 3(P<0.005)$. Conclusions High recanalization rates, low complication rates, and a significantly improved outcome after successful recanalization strongly suggest that MT with pREset is an adequate therapy for AIS after MCA occlusion. Vessel curvature is a significant determining factor for recanalization success.

Keywords Stroke Mechanical thrombectomy ·

Stent retriever · pREset - MCA occlusion ·

Vessel anatomy

List of Abbreviations

AIS Acute ischemic stroke

cCT Cranial Computed Tomography

ICH Intracerebral hemorrhage

MCA Middle cerebral artery

mRS Modified Rankin scale

MT Endovascular mechanical thrombectomy

NIHSS National Institutes of Health Stroke Scale

RCT Randomized controlled trial

rtPA Recombinant tissue plasminogen activator

SAH Subarachnoid hemorrhage

SOP Standard operating procedure

TICI Modified thrombolysis in cerebral infarction score 


\section{Introduction}

Acute ischemic stroke (AIS) is one of the leading causes of morbidity and mortality in industrialized countries, with increasing importance due to the aging population [1]. While data suggest that intravenous thrombolysis using recombinant tissue plasminogen activator (IV rtPA) is barely effective in large-vessel occlusion [2-4], devices and techniques for endovascular mechanical thrombectomy (MT) improved rapidly in the past years.

Initially, previous randomized controlled trials (RCT), which analyzed clinical outcome after the treatment of AIS, after using first-generation devices such as the Penumbra aspiration system (Penumbra, Alameda, CA, USA) or Merci Retriever (Concentric Medical, Mountain View, CA, USA), showed no significant superiority of MT over IV rtPA [5-7].

Simultaneously, second-generation self-expanding, removable, stent-like thrombectomy devices - named stent retrievers - were developed. They are designed to be deployed within the thrombus, where the stent mesh partially penetrates the thrombotic material while expanding. This leads to adhesion of the clot to the stent retriever wall. Both the device and the thrombus are then retrieved into an aspiration or guiding catheter.

More recent studies compared these modern devices with the first-generation devices, which were predominantly used in the initial trials, and reported an explicit superiority of stent retrievers, particularly regarding highly increased recanalization rates and significantly improved clinical outcome [8-17].

Due to these recent findings, the value and validity of the conclusions of the initial RCTs were debated, and concurrently, further advanced MT devices were developed.

In this study, we report our first clinical experiences with the pREset thrombectomy retriever (phenox, Bochum, Germany). Mordasini et al. [18] recently described experimental results of this device in a swine model. Recanalization rates have been reported to be $93.8 \%$ for complete recanalization (modified thrombolysis in cerebral infarction score (TICI) 3 ) and $6.2 \%$ for partial recanalization (TICI $2 b$ ), which are comparable to results of previous animal models, evaluating the Solitaire FR Revascularization Device (Covidien, Dublin, Ireland) and Trevo Retriever (Concentric Medical, Mountain View, CA, USA) devices [19-21]. Kurre et al. [22] recently described the first clinical experience using the pREset for the treatment of AIS. An overall rate of successful recanalization (TICI $2 \mathrm{~b} / 3$ ) of $94.8 \%$ was reported, while including patients with occlusion of the carotid-T, M1, and M2 segments as well as vessels of the posterior circulation (i.e., V4 segment, basilar artery, and P1 segment).

In this study, we focused on a homogenous population of patients with one-sided occlusion of the first middle cerebral artery (MCA) segment (M1 segment) only. We analyzed recanalization efficacy, complication rates, MCA anatomy, and clinical and functional outcome and distinguished patient groups according to technical success of recanalization.

\section{Materials and Methods}

Patients, Therapy Strategy, and Clinical Data

Between October 2011 and November 2012, 48 patients (mean age \pm standard deviation (SD), $71.0 \pm 11.9$ years; 24 women) with symptomatic AIS induced by occlusion of either the left or the right M1 segment of the MCA were treated with MT using the pREset device either solely or in combination with several different devices. These patients were identified retrospectively searching our institution's database, while complete imaging data, clinical reports, and procedure details were mandatory inclusion criteria.

Following our institution's standard operating procedures (SOPs), a relevant neurological deficit of at least four points according to the National Institutes of Health Stroke Scale (NIHSS) was required for therapy.

Preinterventionally, IV rtPA was applied within a time frame of $4.5 \mathrm{~h}$ after observed symptom onset if there were no contraindications, following the guidelines by the German Society of Neurology [23]. Patients received a dose of $0.9 \mathrm{mg}$ rtPA per kilogram of their body weight, whereupon $10 \%$ of the total dose was applied as immediate loading dose and the remaining $90 \%$ during the following hour. IV rtPA was continued until the full dose was administered, regardless of whether angiography and MT were commenced in the meantime.

MT was performed in patients with an MCA occlusion in the M1-segment that presented within a time frame of $6 \mathrm{~h}$ after symptom onset or $3 \mathrm{~h}$ after discovery in wake-up stroke patients. Contraindications for MT were intracranial hemorrhage and distinct infarct demarcation of more than one-third of the MCA territory in initial cranial computed tomography (cCT).

NIHSS score was assessed at admission by an experienced stroke neurologist for baseline evaluation of the patient's clinical status [24, 25]. NIHSS score was reassessed at discharge in 47 patients $(97.9 \%)$. NIHSS score differences were calculated between the scores at admission and discharge, while an improvement of at least four points was considered significant. The degree of dependence was assessed using the modified Rankin Scale (mRS) at discharge in 46 patients $(95.8 \%)$ and after a mean followup time of 205 days $(\mathrm{SD}, \pm 135.6)$ in 43 patients $(89.6 \%)$ through either a standardized telephone or personal interview by trained physicians or evaluated medical reports 
compiled by the respective rehabilitation clinic [26]. An mRS score of 0-2 was defined as favorable outcome.

Time durations were measured: from symptom onset to groin puncture, from symptom onset to reperfusion or end of procedure in case of unsuccessful recanalization, and from groin puncture to reperfusion or end of procedure. In five cases, time from symptom onset to femoral artery puncture was imprecise, but definitely ranged within the time window of $6 \mathrm{~h}$, and no infarct demarcation was shown on the native $\mathrm{cCT}$ scan immediately before intervention.

\section{Imaging Data}

All patients underwent a cCT scan either on a 64-row or a 256-row CT scanner (Philips Brilliance 64/Brilliance iCT; both Philips Medical Systems B.V., Best, the Netherlands) immediately at admission, to rule out hemorrhage or infarct demarcation. In addition, a CT angiography was performed to verify the occlusion type and to analyze vessel pattern. Within $24 \mathrm{~h}$ after endovascular treatment and in case of clinical deterioration, a further $\mathrm{cCT}$ or magnetic resonance imaging (MRI) scan was performed to assess postprocedural complications. The complete imaging data including angiograms were re-evaluated for this study by two neuroradiologists in consensus reading (S. Prothmann and B.J. Schwaiger).

\section{The pREset Device}

The pREset device is a laser-cut nitinol stent, inseparably attached to a $180-\mathrm{cm}$ pusher wire (Fig. 1). The stent wall design features a closed-cell pattern, while a slit is left out that spirals the wall in a helical pattern. This allows the device to expand and contract depending on the vessel diameter, while sustaining the cell configuration, according to manufacturer's information. The proximal cells merge into a closed ring, which is eccentrically connected to the

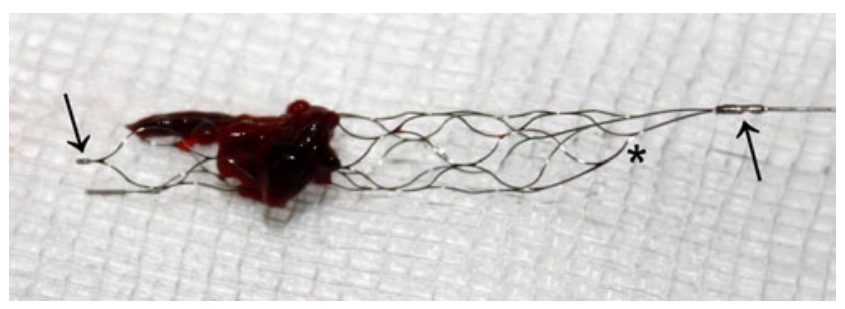

Fig. 1 The pREset 4/20 in clinical use. The image shows the fully expanded device with its closed-cell structure connected to a proximal closed ring (asterisk), which eccentrically merges into the pusher wire (right arrow). At this connection point, there is one radiopaque marker, while there are two more at the distal end of the working length (left arrow). Note the thrombotic material retrieved out of the M1 segment of a 56-year-old female patient, whose final angiogram was graded TICI 3 after two passages pusher wire. This configuration intends to stabilize the proximal opening of the device, to provide a constant radial force, and therefore especially avoids tapering in curved vessels. There is one radiopaque marker at the connection point between the proximal ring and the pusher wire, and there are two additional markers at the most distal ends of the cell structure. The pREset is available in two different sizes, $4 / 20$ and $6 / 30$, where the first number represents the maximal diameter in millimeters and the latter the usable length. As usable length, the manufacturer determines the distance between the distal markers and the closed ring at the proximal end of the device. The device was CE marked in Europe in August 2011. For this retrospective analysis, the pREset $4 / 20$ was used solely.

\section{Endovascular Treatment and Evaluation}

Depending on patients' compliance, endovascular procedures were performed under general anesthesia in 41 patients $(85.4 \%)$, while the remaining patients were treated under conscious sedation and analgesia. An $8 \mathrm{~F}$ guiding catheter (Vista Brite Tip, Cordis) for cervical access was placed through a short $8 \mathrm{~F}$ sheath after puncture of the femoral artery. By a three-axial approach, a 0.054inch intermediate catheter (5MAX, Penumbra) containing a 0.021 -inch microcatheter (Trevo Pro 18, Stryker) and a 0.014-inch microwire (Traxcess 14, Terumo) was advanced intracranially. The occluded M1 segment was passed with the microwire and the microcatheter. In this position, the pREset was deployed, covering the proximal and the distal thrombus borders. After a delay of $5 \mathrm{~min}$, the intermediate catheter was advanced to the proximal thrombus site using the deployed stent retriever as an anchor. Subsequently, the device was retrieved under constant manual aspiration into the intermediate catheter. In two patients, a balloonequipped guiding catheter (Merci Balloon Guided Catheter, Stryker) without an intermediate catheter was used instead of the guiding catheter mentioned, following the individual decision of the interventionalist.

This procedure was repeated until successful recanalization was achieved, or it was aborted in case of excessive procedural time and negligible chances for success. In this analysis, the pREset device was used as first-line device and in combination with other devices in 15 patients $(31 \%)$, according to the performing interventionalist's individual decision.

Recanalization results were graded in the final angiogram using the modified thrombolysis in cerebral infarction score (TICI). TICI of $2 b$ and 3 were considered as successful recanalization [27].

Additionally, anterior-posterior (AP) projections of the final angiograms were assessed for MCA anatomy evaluation (Fig. 2). Similar to the technique described by Zhu 
Fig. 2 Baseline (a) and final (b) angiograms of the right internal carotid artery and the right MCA of a 73-year-old male patient. The angle between the proximal, nearly horizontal part and the more distal part of the M1 segment after the curvature measures $104.6^{\circ}$. After four futile passages with $\mathrm{pREset}$ and Solitaire stent retrievers, the procedure was discontinued and the final angiogram was graded as TICI 0
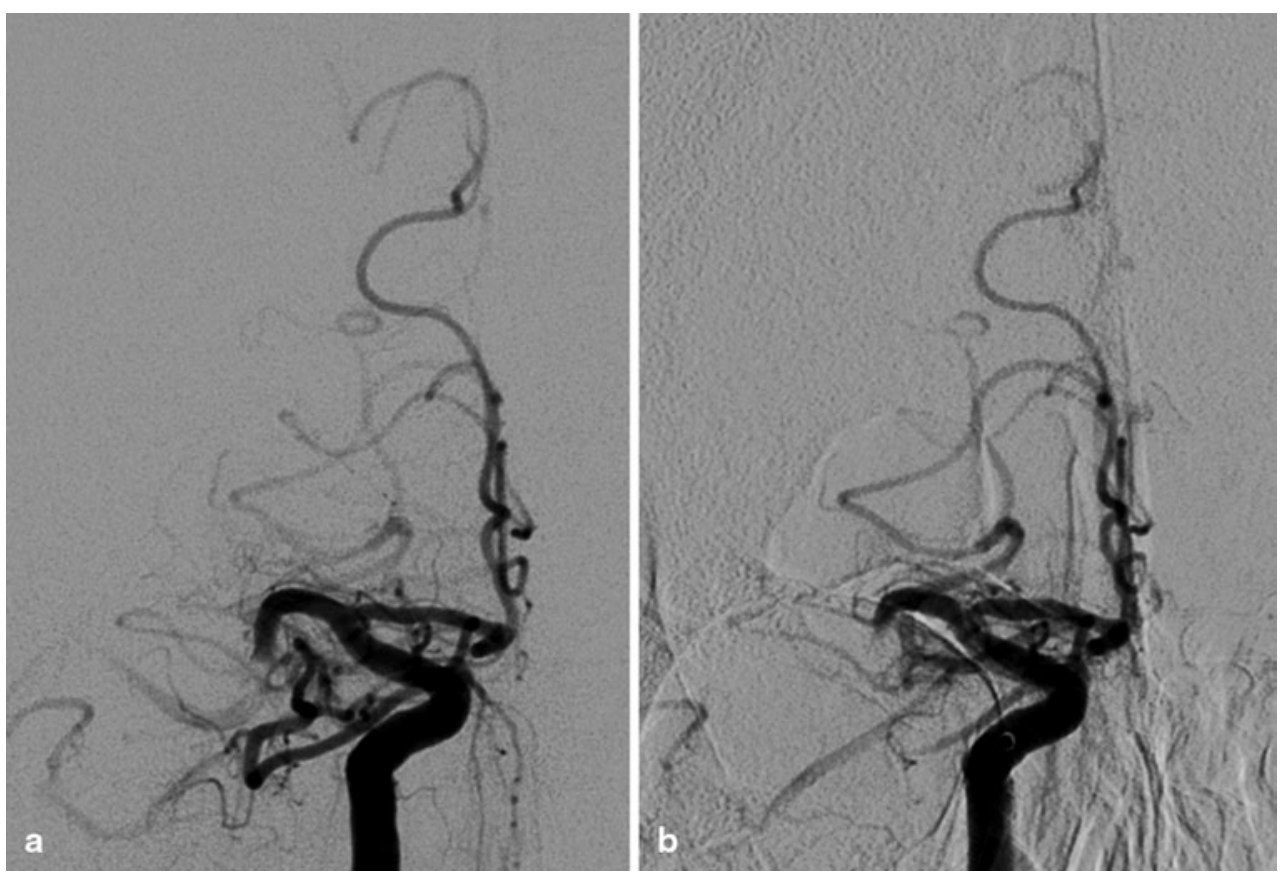

et al. [28], and to the experience of our interventionalists, the curvature angle between the most proximal part immediately emerging out of the carotid-T and the most distally contrasted part of the M1 segment was measured. A curvature angle exceeding $80^{\circ}$ was defined as curved MCA.

Perforation, dissection, thrombus dispersion, and focal or diffuse subarachnoid hemorrhage (SAH) were determined as procedure-related complications. Separately, strokerelated hemorrhagic events (hemorrhagic infarction and parenchymal hematoma) were characterized according to the methods used in the ECASS trials [29]. Complications and hemorrhage were defined as clinically relevant if they were associated with an NIHSS score increase of four points or more.

\section{Statistical Analysis}

In addition to descriptive statistics, Fisher's exact test was used for categorical data, the exact Mann-Whitney $U$ test for nonparametric testing, and Student's or Welch's $t$-test for continuous data, depending on equality of variances. All tests were performed using a two-sided 0.05 level of significance. Statistical analyses were performed using IBM SPSS Statistics, release 21 (IBM, Armonk, NY, USA) and supervised by a statistician.

\section{Results}

A total of 48 consecutive patients (mean age \pm SD, $71.0 \pm 11.9$ years, 24 female) were included in the study (Table 1). Median NIHSS score at admission was 15 (range, 2-27).
Three patients were admitted after wake-up stroke with unknown time from symptom onset to reperfusion, while in the remaining patients, mean time between observed symptom onset and groin puncture was $246 \mathrm{~min}(\mathrm{SD}, \pm 88.0 \mathrm{~min}$ ). The average procedure time was $54 \mathrm{~min}(\mathrm{SD}, \pm 35.6 \mathrm{~min}$ ). Between subgroups of patients with versus without successful recanalization, there were no significant differences in demographic parameters, NIHSS score at admission, and reported time windows.

A successful recanalization (TICI $2 b / 3$ ) was achieved in 39 patients $(81.3 \%)$. Concerning the analysis of vessel configuration, patients with a curved MCA were significantly more often recanalized unsuccessfully than those with a less angulated MCA (2.6 versus $44.4 \% ; P<0.005$ ).

Focal SAH was found in five patients $(10.4 \%)$ on the 24-h follow-up images, while none of these patients presented clinical worsening. Diffuse SAH was not found in any patient. In one patient (2.1\%), SAH was observed during the procedure, while a definite vessel perforation was not detected. To achieve hemostasis in one case of a documented microwire perforation, one frontal MCA branch was occluded using a single fiber coil, and the final angiogram was graded TICI $2 b$ at the end of the procedure. In this patient, there was no SAH-related clinical worsening as well and he was discharged, showing an NIHSS score of 7 . At follow-up, he presented with an mRS score of 2 . In one patient $(2.1 \%)$, a dissection of the cervical segment of the internal carotid artery was induced by inflation of a cathetermounted balloon. As no hemodynamic effect was recorded in the final angiogram as well as sonographically immediately after the procedure, no further therapy was performed. In one patient $(2.1 \%)$, the thrombus was dislocated from the 
Table 1 Epidemiological, clinical, and technical parameters as well as outcome of all patients and comparison between subgroups depending on recanalization success

\begin{tabular}{|c|c|c|c|c|}
\hline Parameter & All patients & TICI $0-2 \mathrm{a}$ & TICI $2 b / 3$ & $P$-value \\
\hline Group/subgroup size & 48 & $9(18.7 \%)$ & $39(81.3 \%)$ & \\
\hline $\begin{array}{l}\text { Female sex ( } n ; \% \text { of } \\
\text { subgroup) }\end{array}$ & $24(50 \%)$ & $3(33.3 \%)$ & $21(53.8 \%)$ & 0.461 \\
\hline Age (years; mean $\pm \mathrm{SD}$ ) & $71.0 \pm 11.9$ & $66.4 \pm 10.4$ & $72.1 \pm 12.1$ & 0.203 \\
\hline $\begin{array}{l}\text { Wake-up ( } n ; \% \text { of } \\
\text { subgroup) }\end{array}$ & $3(6.3 \%)$ & $0(0.0 \%)$ & $3(7.7 \%)$ & 1,000 \\
\hline $\begin{array}{l}\text { Time from symptom onset } \\
\text { to puncture (min; mean } \\
\pm \mathrm{SD})^{\mathrm{a}}\end{array}$ & $246 \pm 88.0$ & $229 \pm 124.1$ & $249 \pm 81.1$ & 0.573 \\
\hline $\begin{array}{l}\text { Procedure time (min; mean } \\
\pm \mathrm{SD})^{\mathrm{b}}\end{array}$ & $54 \pm 35.6$ & $67 \pm 42.2$ & $51 \pm 34.3$ & 0.276 \\
\hline $\begin{array}{l}\text { Time from onset to recana- } \\
\text { lization (min; mean } \pm \mathrm{SD})^{\mathrm{a}}\end{array}$ & $299 \pm 94.9$ & $296 \pm 139.3$ & $300 \pm 86.5$ & 0.920 \\
\hline $\begin{array}{l}\text { IV rTPA administered ( } n ; \\
\% \text { of subgroup) }\end{array}$ & $34(65.4 \%)$ & $4(44.4 \%)$ & $30(76.9 \%)$ & 0.099 \\
\hline $\begin{array}{l}\text { Passages of device ( } n \\
\text { median, range) }\end{array}$ & $2(1$ to 8$)$ & $4(1$ to 8$)$ & $2(1$ to 6$)$ & $0.023 *$ \\
\hline $\begin{array}{l}\text { More than one device used } \\
\text { ( } n ; \% \text { of subgroup) }\end{array}$ & $16(33.3 \%)$ & $6(66.7 \%)$ & $10(25.6 \%)$ & $0.044 *$ \\
\hline $\begin{array}{l}\text { Curved MCA ( } n ; \% \text { of } \\
\text { subgroup) }\end{array}$ & $5(10.4 \%)$ & $4(44.4 \%)$ & $1(2.6 \%)$ & $0.003 *$ \\
\hline $\begin{array}{l}\text { NIHSS score at admission } \\
\text { (median, range) }\end{array}$ & 15 (2 to 27$)$ & 15 (9 to 24$)$ & 15 (2 to 27$)$ & 0.912 \\
\hline $\begin{array}{l}\text { NIHSS score at discharge } \\
\text { (median, range) }^{c}\end{array}$ & $7(0$ to 43$)$ & 11 (3 to 43$)$ & $5(0$ to 43$)$ & $0.018 *$ \\
\hline $\begin{array}{l}\text { NIHSS improvement } \\
\text { (median, range) }^{c}\end{array}$ & $-7(-20$ to 34$)$ & $0(-8$ to 34$)$ & $-7(-20$ to 30$)$ & 0.094 \\
\hline $\begin{array}{l}\text { NIHSS improvement more } \\
\text { than four points }(n ; \% \text { of } \\
\text { subgroup })^{c}\end{array}$ & $34(72.3 \%)$ & $4(44.4 \%)$ & $30(76.9 \%)$ & 0.191 \\
\hline $\begin{array}{l}\text { mRS score 0-2 at } \\
\text { discharge }^{\mathrm{b}}\end{array}$ & $17(37.0 \%)$ & $0(0 \%)$ & $17(45.9 \%)$ & $0.017 *$ \\
\hline $\begin{array}{l}\text { mRS score } 0-2 \text { at } \\
\text { follow-up }\end{array}$ & $18(41.9 \%)$ & $1(12.5 \%)$ & $17(48.6 \%)$ & 0.111 \\
\hline $\begin{array}{l}\text { Death within } 90 \text { days ( } n \text {; } \\
\% \text { of subgroup })^{\mathrm{a}}\end{array}$ & $8(18.6 \%)$ & $5(62.5 \%)$ & $3(8.6 \%)$ & $0.003 *$ \\
\hline
\end{tabular}

Data missing for $n$ patients $\left({ }^{\mathrm{a}} n=5 ;{ }^{\mathrm{b}} n=2 ;{ }^{\mathrm{c}} n=1\right)$

*Significant on the level $P<0.05$

proximal section to the distal section of the M1 segment, while a small thrombus fragment was scattered and embolized into a small frontal MCA branch. After a further successful passage, the final angiogram was graded TICI $2 \mathrm{~b}$, and the patient was discharged, presenting an NIHSS score of 0 . A hemodynamically relevant vasospasm of the M1 segment was observed in one patient $(2.6 \%)$, after three passages with two different devices (pREset and Trevo 4/20). With a delay of $5 \mathrm{~min}$, the vasospasm remitted spontaneously, and consequently no further therapy was performed. However, only partial recanalization was achieved in this patient (TICI 2a), and at discharge, the patient presented an NIHSS score of 10.

According to the ECASS classification for hemorrhagic events, there were four patients $(8.3 \%)$ with small petechial hemorrhagic infarction (HI1) and eight patients (16.7\%) with more confluent petechial hemorrhagic infarction (HI2), while three patients $(6.3 \%)$ showed parenchymal hematoma with mild space-occupying effect (PH1) and one patient (2.1\%) showed significant space-occupying effect (PH2). In none of these cases, hemorrhage was considered as clinically relevant. Regarding hemorrhage rates, there were no significant differences between the TICI $0-2 \mathrm{a}$ and TICI $2 \mathrm{~b} / 3$ subgroups.

Patients in the TICI $2 b / 3$ subgroup had significantly lower absolute NIHSS values at discharge compared with patients in the TICI 0-2a subgroup (median, 5 versus 11; $P<0.05$ ), while no significant differences between the subgroups were found in NIHSS improvement, which is defined as the difference between NIHSS score at admis- 
sion and discharge. Successful recanalization was significantly associated with favorable mRS values at discharge (45.9 versus $0.0 \% ; P<0.05$; Fig. 3 ). At follow-up, patients of the TICI $2 \mathrm{~b} / 3$ subgroup showed a good functional outcome more often $(\mathrm{mRS}$ score $\leq 2)$ than those of the TICI 0 -2a subgroup; however, this difference was not significant (48.6 versus $12.5 \% ; P>0.05$ ). Mortality within 90 days was significantly lower in patients in the TICI $2 b / 3$ subgroup (8.6 versus $62.5 \%$; $P<0.005$; Fig. 3 ).

No significant influence of IV rtPA application on recanalization success or any of the analyzed clinical and functional outcome parameters was found $(P>0.05)$.

Patients treated under general anesthesia had significantly higher NIHSS scores at admission than patients treated under conscious sedation and analgesia $(P<0.05)$, while the NIHSS score differences after MT treatment did not differ significantly between these patients $(P>0.05)$. Technical recanalization results and $\mathrm{mRS}$ scores at follow-up were not influenced significantly by the type of anesthesia $(P>0.05)$.
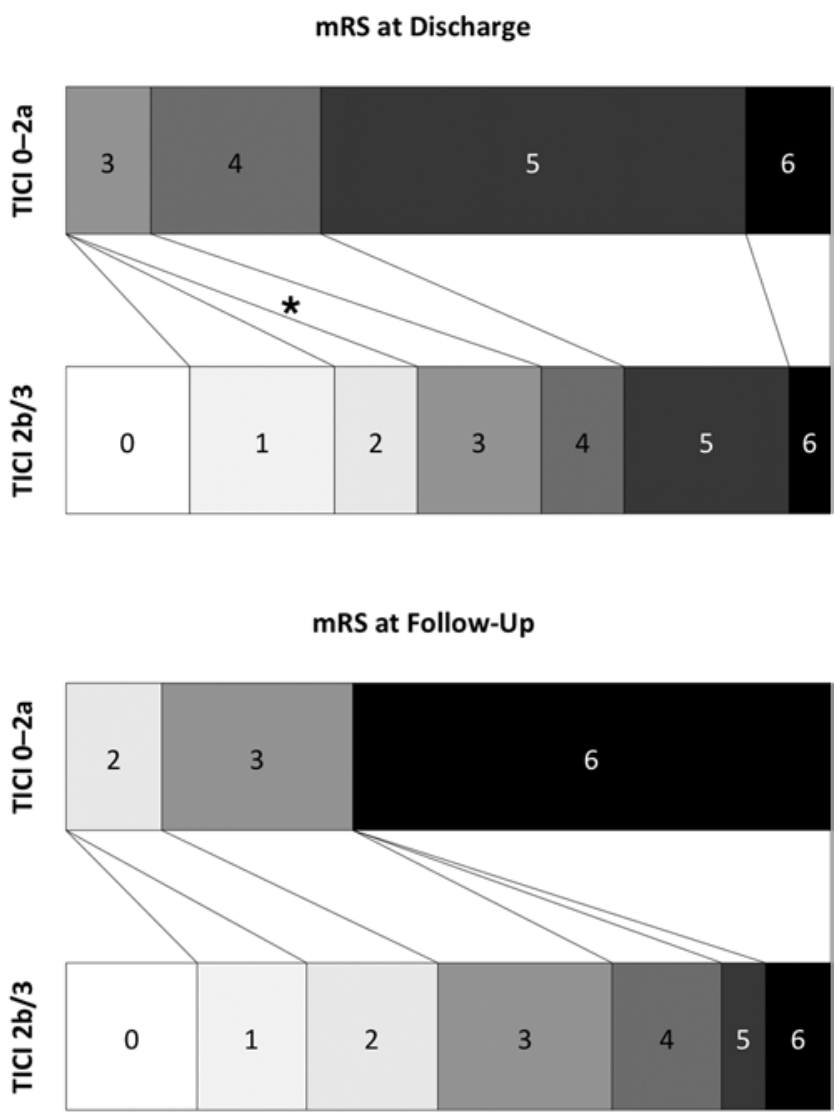

Fig. 3 Shift analyses showing mRS values at discharge and followup of patients after successful (TICI $2 \mathrm{~b} / 3$ ) versus unsuccessful (TICI $0-2 a)$ recanalization. After successful recanalization, significantly more patients presented a favorable outcome (mRS score 0-2) at discharge (asterisk, $P<0.05$ ). At follow-up, however, this distinct trend was not statistically significant

\section{Discussion}

In this study, we have shown that treatment of AIS caused by MCA occlusion using the pREset stent retriever is associated with high recanalization rates and a low risk of procedurerelated complications such as vessel perforation, dissection, or thrombus dispersion. These findings are congruent with the results of the experimental in vivo model, as reported by Mordasini et al. [18], as well as with the first clinical experience with the same device, as reported by Kurre et al. [22]. In contrast to the latter, in which patients with different occlusion patterns of the anterior and posterior circulation were included, we focused on patients with MCA M1 segment occlusion only. Kurre et al. reported recanalization rates of $76.4 \%$ within three passages with the pREset device solely and $94.8 \%$ overall (if the number of passages or number of different devices used was not taken into consideration). These results are comparable to the recanalization rate of $81.3 \%$, which was achieved in this study.

Many recent studies show the superiority of stent retrievers over first-generation devices regarding recanalization success [8-17]. Recanalization rates achieved in this study are comparable to rates reported by a multicenter evaluation of the Solitaire $(79.2 \%)$ and a combined analysis of Solitaire and Trevo $(82 \%)$ [12, 30]. Also, adverse event rates are comparable to those reported $(7.4-10 \%)[12,17,30]$.

Recanalization rates correlated significantly negatively with the number of passages necessary as well as with the number of different devices used. This is plausible, as, for example, in patients with complicated vessel geometry or resistant thrombus composition, different technical approaches are attempted, often leading to poor final results, irrespective of the number of passages.

The potential to identify factors determining recanalization success was limited in this retrospective study. However, we analyzed the anatomy of the M1 segment in correlation with recanalization results. To our knowledge, the influence of vessel anatomy, assessed in angiograms, on recanalization results has not been investigated before. There is only one previous study based on pre-interventional MRI. Zhu et al. [28] analyzed clot shape and vessel curvature as shown by the susceptibility vessel sign in axial $\mathrm{T} 2 *$ gradient echo sequences, and its influence on recanalization results. The curved shape of the MCA significantly diminished chances for technical and clinical success of MT using the MERCI retriever, a first-generation thrombectomy device, which is obsolete in most cases by now. However, the effects of vessel curvature concerning the efficacy of second-generation devices such as Solitaire, Trevo, or pREset remained unclear so far. In this study population, we have found that in patients presenting an MCA curvature with more than $80^{\circ}$ measured in the AP-projection angiogram, a successful recanalization is significantly less likely. It has to be noted 
that larger study populations treated with different stent retrievers need to be analyzed to further understand this findings entity, especially considering the performance of different devices in curved vessels.

Dissection of a cervical vessel, thrombus dispersion, and hemodynamically relevant vasospasm each was detected only in one patient $(2.1 \%)$. We observed focal SAH after thrombectomy in five patients $(10.4 \%)$, which is comparable to SAH rates of $3.5-16.2 \%$ as reported before $[9,31-33]$. None of those was associated with clinical deterioration. This is congruent to recent publications showing no significant influence of focal periprocedural SAH on clinical outcome $[33,34]$. In one patient $(2.1 \%)$, SAH was diagnosed during intervention, although no vessel perforation was registered. Parenchymal hematoma (ECASS PH1 + PH2) was detected in $8.3 \%$ and hemorrhagic infarction (ECASS HI $1+$ HI2) in $25 \%$ of the patients, which is also comparable to previous results using stent retrievers $(3.5-22.8 \%)[11,12,22$, 30]. However, as shown in previous studies, a direct causal link between MT and hemorrhagic events was not found. In summary, procedure-related complication rates were equal or lower compared with a recent review [35].

Both the SWIFT and TREVO trial reported a higher rate of favorable mRS values at follow-up (58 and 55\%) [14, 36]. However, the patient populations of these RCT differed from the patients included in this study. For example, mean age of our patients was higher than that reported by SWIFT and TREVO $(71.0 \pm 11.9$ versus $67.1 \pm 12.0$ and $64.7 \pm 13.4$ years, respectively). Also, patients after wake-up stroke were included in our study, in contrast to those trials. This suggests that different inclusion and exclusion criteria may impede the comparison of results reported by recent and planned trials on MT.

Compared with the results reported by postmarketing registries such as the North American Solitaire Stent Retriever Registry (42\%) and the European Endostroke Registry (41\%), the percentage of patients included in this study presenting with a favorable neurological outcome (mRS score 0-2) at mid-term follow-up was very similar $(41.9 \%)[17,37]$.

Our data showed a significant influence of technical recanalization success on the clinical and functional outcome at discharge. Of note, there was no patient after unsuccessful or incomplete recanalization who had a favorable mRS score at discharge. At follow-up, no patient of the TICI $0-2$ a subgroup showed an mRS value of 0 or 1 . Also, correlation between recanalization success and death within 90 days was highly significant.

MT with the pREset, therefore, has the potential to improve the treatment of AIS caused by MCA occlusion. The data provided by this and similar studies generally demonstrate the potential benefit of stent retrievers outweighing the procedure-related risks.
$85.4 \%$ of the patients included in this study were treated under general anesthesia, which is comparable to the numbers reported by the ENDOSTROKE registry (93\%) [38]. However, due to the small sample size, we were not able to analyze the impact of anesthesia type on recanalization success.

This retrospective analysis focused primarily on the safety and technical efficacy of the pREset device. We also analyzed mid-term clinical outcome; however, a standardized 3-month follow-up was not yet part of our institutional SOPs at the time the patients were treated. As a result, there was an increased variance in follow-up time, which diminished the value of clinical mid-term follow-up data. Another limitation of the study was the small size of the TICI 0-2a subgroup. Subsequently, logistic regression models or other statistical means suitable for larger analyses were considered as unstable, and more robust tests not correcting for age, recanalization times, or comorbidities, for example, had to be employed. That no significant differences between the subgroups were found regarding NIHSS improvement and $\mathrm{mRS}$ at follow-up may be caused by these limitations.

\section{Conclusion}

This clinical data presented showed high recanalization rates and low complication rates in patients treated with the pREset stent retriever. Patients showed a significant clinical outcome improvement after successful recanalization. These findings suggest that MT with the pREset, representing second-generation thrombectomy devices, is an adequate therapy for AIS induced by MCA occlusion. The finding that recanalization success is significantly influenced by MCA anatomy should further be investigated.

Acknowledgement The authors thank Jana Jarecki for statistical advice. The manuscript has not been published or presented before.

\section{Funding No funding.}

Conflicts of Interest S. Prothmann is a proctor for phenox. All other authors declare that they have no conflict of interest.

Ethical Standards Statement This study has been approved by the local ethics committee, and has been performed in accordance with the ethical standards laid down in the 1964 Declaration of Helsinki and its later amendments.

\section{References}

1. Seshadri S, Wolf PA. Lifetime risk of stroke and dementia: current concepts, and estimates from the Framingham Study. Lancet Neurol. 2007;6(12):1106-14. doi:10.1016/S1474-4422(07)70291-0. 
2. Mori E, Yoneda Y, Tabuchi M, Yoshida T, Ohkawa S, Ohsumi Y, et al. Intravenous recombinant tissue plasminogen activator in acute carotid artery territory stroke. Neurology. 1992;42(5):976-82.

3. Saqqur M, Uchino K, Demchuk AM, Molina CA, Garami Z, Calleja $\mathrm{S}$, et al. Site of arterial occlusion identified by transcranial Doppler predicts the response to intravenous thrombolysis for stroke. Stroke. 2007;38(3):948-54. doi:10.1161/01. STR.0000257304.21967.ba.

4. Smith WS, Lev MH, English JD, Camargo EC, Chou M, Johnston $\mathrm{SC}$, et al. Significance of large vessel intracranial occlusion causing acute ischemic stroke and TIA. Stroke. 2009;40(12):3834-40. doi:10.1161/STROKEAHA.109.561787.

5. Broderick JP, Tomsick TA, Palesch YY. Endovascular treatment for acute ischemic stroke. N Engl J Med. 2013;368(25):2432-3. doi:10.1056/NEJMc1304759.

6. Ciccone A, Valvassori L, Nichelatti M, Sgoifo A, Ponzio M, Sterzi $\mathrm{R}$, et al. Endovascular treatment for acute ischemic stroke. N Engl J Med. 2013;368(10):904-13. doi:10.1056/NEJMoa1213701.

7. Kidwell CS, Jahan R, Gornbein J, Alger JR, Nenov V, Ajani Z, et al. A trial of imaging selection and endovascular treatment for ischemic stroke. N Engl J Med. 2013;368(10):914-23. doi:10.1056/ NEJMoa1212793.

8. Castano C, Dorado L, Guerrero C, Millan M, Gomis M, Perez de la Ossa N, et al. Mechanical thrombectomy with the Solitaire $\mathrm{AB}$ device in large artery occlusions of the anterior circulation: a pilot study. Stroke. 2010;41(8):1836-40. doi:10.1161/ STROKEAHA.110.584904.

9. Davalos A, Pereira VM, Chapot R, Bonafe A, Andersson T, Gralla $\mathrm{J}$, et al. Retrospective multicenter study of Solitaire FR for revascularization in the treatment of acute ischemic stroke. Stroke. 2012;43(10):2699-705. doi:10.1161/STROKEAHA.112.663328.

10. Fischer U, Mono ML, Schroth G, Jung S, Mordasini P, El-Koussy M, et al. Endovascular therapy in 201 patients with acute symptomatic occlusion of the internal carotid artery. Eur $\mathrm{J}$ Neurol. 2013;20(7):1017-24, e87. doi:10.1111/ene.12094.

11. Nogueira RG, Lutsep HL, Gupta R, Jovin TG, Albers GW, Walker GA, et al. Trevo versus Merci retrievers for thrombectomy revascularisation of large vessel occlusions in acute ischaemic stroke (TREVO 2): a randomised trial. Lancet. 2012;380(9849):1231-40. doi:10.1016/S0140-6736(12)61299-9.

12. Pereira VM, Gralla J, Davalos A, Bonafe A, Castano C, Chapot $\mathrm{R}$, et al. Prospective, multicenter, single-arm study of mechanical thrombectomy using Solitaire Flow Restoration in acute ischemic stroke. Stroke. 2013;44(10):2802-7. doi:10.1161/ STROKEAHA.113.001232.

13. San Roman L, Obach V, Blasco J, Macho J, Lopez A, Urra X, et al. Single-center experience of cerebral artery thrombectomy using the TREVO device in 60 patients with acute ischemic stroke. Stroke. 2012;43(6):1657-9. doi:10.1161/STROKEAHA.111.640011.

14. Saver JL, Jahan R, Levy EI, Jovin TG, Baxter B, Nogueira RG, et al. Solitaire flow restoration device versus the Merci Retriever in patients with acute ischaemic stroke (SWIFT): a randomised, parallel-group, non-inferiority trial. Lancet. 2012;380(9849):1241-9. doi:10.1016/S0140-6736(12)61384-1.

15. Stampfl S, Hartmann M, Ringleb PA, Haehnel S, Bendszus M, Rohde S. Stent placement for flow restoration in acute ischemic stroke: a single-center experience with the Solitaire stent system. AJNR Am J Neuroradiol. 2011;32(7):1245-8. doi:10.3174/ajnr. A2505.

16. Yoon YH, Yoon W, Jung MY, Yim NY, Kim BC, Kang HK. Outcome of mechanical thrombectomy with Solitaire stent as firstline intra-arterial treatment in intracranial internal carotid artery occlusion. Neuroradiology. 2013;55(8):999-1005. doi:10.1007/ s00234-013-1205-2.
17. Zaidat OO, Castonguay AC, Gupta R, Sun CH, Martin C, Holloway WE, et al. North American Solitaire Stent Retriever Acute Stroke registry: post-marketing revascularization and clinical outcome results. J Neurointerv Surg. 2013. doi:10.1136/ neurintsurg-2013-010895.

18. Mordasini P, Brekenfeld C, Byrne JV, Fischer U, Arnold M, Jung $\mathrm{S}$, et al. Experimental evaluation of immediate recanalization effect and recanalization efficacy of a new thrombus retriever for acute stroke treatment in vivo. AJNR Am J Neuroradiol. 2013;34(1):153-8. doi:10.3174/ajnr.A3275.

19. Mordasini P, Frabetti N, Gralla J, Schroth G, Fischer U, Arnold M, et al. In vivo evaluation of the first dedicated combined flow-restoration and mechanical thrombectomy device in a swine model of acute vessel occlusion. AJNR Am J Neuroradiol. 2011;32(2):294300. doi:10.3174/ajnr.A2270.

20. Jahan R. Solitaire flow-restoration device for treatment of acute ischemic stroke: safety and recanalization efficacy study in a swine vessel occlusion model. AJNR Am J Neuroradiol. 2010;31(10):1938-43. doi:10.3174/ajnr.A2169.

21. Nogueira RG, Levy EI, Gounis M, Siddiqui AH. The Trevo device: preclinical data of a novel stroke thrombectomy device in two different animal models of arterial thrombo-occlusive disease. J Neurointerv Surg. 2012;4(4):295-300. doi:10.1136/ neurintsurg-2011-010053.

22. Kurre W, Aguilar-Perez M, Schmid E, Sperber W, Bazner H, Henkes $\mathrm{H}$. Clinical experience with the pREset stent retriever for the treatment of acute ischemic stroke- a review of 271 consecutive cases. Neuroradiology. 2014. doi:10.1007/s00234-014-1346-y.

23. Veltkamp R. Akuttherapie des ischämischen Schlaganfalls. In: Diener HC, Weimar C, editors. Leitlinien für Diagnostik und Therapie in der Neurologie. Stuttgart: Thieme; 2012.

24. Brott T, Adams HP, Jr., Olinger CP, Marler JR, Barsan WG, Biller $\mathrm{J}$, et al. Measurements of acute cerebral infarction: a clinical examination scale. Stroke. 1989;20(7):864-70.

25. Heldner MR, Zubler C, Mattle HP, Schroth G, Weck A, Mono ML, et al. National Institutes of Health stroke scale score and vessel occlusion in 2152 patients with acute ischemic stroke. Stroke. 2013;44(4):1153-7. doi:10.1161/STROKEAHA.111.000604.

26. van Swieten JC, Koudstaal PJ, Visser MC, Schouten HJ, van Gijn J. Interobserver agreement for the assessment of handicap in stroke patients. Stroke. 1988;19(5):604-7.

27. Higashida RT, Furlan AJ, Roberts H, Tomsick T, Connors B, Barr J, et al. Trial design and reporting standards for intra-arterial cerebral thrombolysis for acute ischemic stroke. Stroke. 2003;34(8):e109_ 37. doi:10.1161/01.STR.0000082721.62796.09.

28. Zhu L, Liebeskind DS, Jahan R, Starkman S, Salamon N, Duckwiler $\mathrm{G}$, et al. Thrombus branching and vessel curvature are important determinants of middle cerebral artery trunk recanalization with Merci thrombectomy devices. Stroke. 2012;43(3):787-92. doi:10.1161/STROKEAHA.110.612986.

29. Berger C, Fiorelli M, Steiner T, Schabitz WR, Bozzao L, Bluhmki E, et al. Hemorrhagic transformation of ischemic brain tissue: asymptomatic or symptomatic? Stroke. 2001;32(6):1330-5.

30. Broussalis E, Trinka E, Hitzl W, Wallner A, Chroust V, KillerOberpfalzer M. Comparison of stent-retriever devices versus the Merci retriever for endovascular treatment of acute stroke. AJNR Am J Neuroradiol. 2013;34(2):366-72. doi:10.3174/ajnr.A3195.

31. Akins PT, Amar AP, Pakbaz RS, Fields JD, Investigators S. Complications of endovascular treatment for acute stroke in the SWIFT trial with solitaire and Merci devices. AJNR Am J Neuroradiol. 2014;35(3):524-8. doi:10.3174/ajnr.A3707.

32. Dorn F, Stehle S, Lockau H, Zimmer C, Liebig T. Endovascular treatment of acute intracerebral artery occlusions with the solitaire stent: single-centre experience with 108 recanalization procedures. Cerebrovasc Dis. 2012;34(1):70-7. doi:10.1159/000338903. 
33. Yoon W, Jung MY, Jung SH, Park MS, Kim JT, Kang HK. Subarachnoid hemorrhage in a multimodal approach heavily weighted toward mechanical thrombectomy with solitaire stent in acute stroke. Stroke. 2013;44(2):414-9. doi:10.1161/ STROKEAHA.112.675546.

34. Yilmaz U, Walter S, Korner H, Papanagiotou P, Roth C, Simgen A, et al. Peri-interventional subarachnoid hemorrhage during mechanical thrombectomy with stent retrievers in acute stroke: a retrospective case-control study. Clin Neuroradiol. 2014. doi:10.1007/s00062-014-0294-6.

35. Walcott BP, Boehm KM, Stapleton CJ, Mehta BP, Nahed BV, Ogilvy CS. Retrievable stent thrombectomy in the treatment of acute ischemic stroke: analysis of a revolutionizing treatment technique. J Clin Neurosci. 2013;20(10):1346-9. doi:10.1016/j. jocn.2013.03.015.
36. Jansen O, Macho JM, Killer-Oberpfalzer M, Liebeskind D, Wahlgren N, TREVO Study Group. Neurothrombectomy for the treatment of acute ischemic stroke: results from the TREVO study. Cerebrovasc Dis. 2013;36(3):218-25. doi:10.1159/000353990.

37. Singer OC, Haring HP, Trenkler J, Nolte $\mathrm{CH}$, Bohner G, Reich A, et al. Age dependency of successful recanalization in anterior circulation stroke: the ENDOSTROKE study. Cerebrovasc Dis. 2013;36(5-6):437-45. doi:10.1159/000356213.

38. Singer O, Haring H-P, Trenkler J, Nolte C, Bohner G, Neumann-Haefelin $\mathrm{T}$, et al. Periprocedural aspects in mechanical recanalization for acute stroke: data from the ENDOSTROKE registry. Neuroradiology. 2013;55(9):1143-51. doi:10.1007/ s00234-013-1219-9. 